\title{
Virtue Theory, Relativism and Survival
}

\author{
Joseph Grcic
}

\begin{abstract}
Virtue theory claims that moral virtues define the moral person. Moral relativism claims there are no necessary universal moral values-this theory is not rationally sustainable as a theory of ethics. The necessary functions of social order and existence require certain moral virtues. There are six main universal moral virtues: wisdom, courage, justice, humanity, temperance, and transcendence. Societies cannot function efficiently without these core virtues.
\end{abstract}

Index terms-Moral relativism, social structure, virtue theory.

\section{INTRODUCTION}

The realm of ethics seems to be one of the most conflicted and uncertain in philosophy and in human history. This conflict would be tolerable if it did not have practical and serious consequences and ramifications in the arena of human action, society, and moral skepticism in general.

To develop an approach towards addressing this critical problem an appropriate methodology must be used. Since the issue involves the interface of ethical values and social structures, an interdisciplinary, historical, comparative, conceptual and logical methodology must be implemented. The findings of sociology, anthropology, psychology and other sciences must be assessed. Further, the contributions of philosophy including various ethical paradigms and tools for logical analysis must be incorporated.

\section{RELATIVISM}

One aspect of the problem of ethical disagreements and skepticism about the rational resolution of moral disputes is the rise of the theory of relativism of which there are several forms. Descriptive or cultural relativism is the factual claim that there are disagreements about morality in different cultures and different times even within one culture. Ethical or moral relativism is the normative view that there is and cannot be no one correct rational morality or set of value for all societies [1]-[3]. Relativism, in its extreme forms, holds that morality is a social construct such that in principle any moral system is possible in any society. [4] It claims nothing can be judged intrinsically, necessarily and universally to be good or evil. Some defenders of relativism see moral systems as ideological in nature whose primary function is to perpetuate the ruling class [5]. Ethical relativism is often a consequence of epistemological relativism and postmodern skepticism which claim that

Manuscript received April 3, 2013; revised June 3, 2013.

Joseph Grcic is with Indiana State University. he is a professor of philosophy, His lastest published book is Free and Equal (e-mail: Joseph.Grcic@indstate.edu) there can be no objective or universal knowledge in any human endeavor including ethics.

Metaethical relativism is the claim that moral concepts have meaning only within a given cultural framework. Any two different normative systems are incommensurable and one cannot be rationally judged to be superior to the other.

Relativism in the extreme form conflicts with the fact that there are similarities in moral virtues found across all stable cultures. These virtues and values are a function of the universality of human nature, human needs and the common problems societies must solve to survive. The differences that do exist in moral norms are limited and arise due to different social and historical contexts, ideologies and belief systems which shape moral norms to some degree. But these differences are secondary when compared to the larger common foundation of core values based on the common problems which must be solved for communities to survive.

\section{VIRTUE THEORY}

Studies of various religious and philosophical traditions show the existence of some universal moral virtues. Perspectives as diverse as Hinduism, Confucianism, Buddhism, Taoism, Judaism, Christianity, Islam, Platonism, Aristotelianism, and others defend six core virtues as necessary for social order and human flourishing. [6] But before examining this claim, a brief explanation of understanding ethics from the perspective of virtues in contrast to other main approaches is needed. Deontology such as that of Kant is a rationalistic view of ethics which rejects any role for emotions and is based on the view of ethics on the nature of the intentions formed and the duties accepted. Teleological ethics such as the utilitarianism of John S. Mill, understands ethics as based on the consequences in terms of happiness caused by actions [7][9].

Virtues are character traits or habits of action which, according to virtue theory, define the moral person. Virtue theory accepts the importance of intentions and consequences but rejects as rationalistic and unrealistic view of ethics in the other approaches and sees ethical actions as combining reason and emotions. A virtue approach sees being ethical as not just deducing specific acts from abstract principles but having a type of character with sound judgment to respond correctly to varied complex circumstances. Virtue ethics grounds moral values in the personality structure and as such provides the necessary motivational element which deontological and teleological paradigms lack. Finally, virtue ethics is open to using the findings of disciplines such as psychology, sociology, anthropology and other disciplines to clarify morality and understand the lived context of human action and how 
moral behavior is generated.

\section{UNIVERSAL VIRTUES}

Six foundational virtues have been discovered to play central roles in cross-cultural traditions and societies [10]. These virtues are not defined in exactly the same manner in all cultures but there is a common core meaning. The virtues are: courage, justice, humanity, temperance, transcendence and wisdom. Courage is defined as the rational response to fear and has three main aspects, physical, moral and psychological. Physical courage is form of courage wherein one overcomes the fear of physical injury or death to save others or oneself. Moral courage means to hold to one's moral beliefs in the face of attacks, and psychological courage concerns the ability to endure and confront personal mental or physical illness or difficult situation.

The virtue of justice concerns treating people fairly in the proper distribution of rights and duties or treating equals equally and unequals unequally. Different theories have been proposed through the ages such as the apostle Paul's command "If any would not work, neither should he eat." (2Thess 3:10) or Plato's theory of a just society as one where everyone performs one's function, what they do best or Marx's idea of "From each according to his ability, to each according to his need" the core idea is the need to meet the needs of society [11], Whether distribution of goods is based on need, contribution, status or some other criteria, there is a common understanding that justice is necessary for the harmonious relations among persons. A just society is also necessary for generating a belief on the part of the populace that the burdens of society are allocated fairly so that the political system is accepted as legitimate which is essential for social stability.

The virtue of humanity concerns altruistic behavior such as actions of generosity and kindness. Actions here go beyond the demands of justice and concerns empathy for others and the reduction of their suffering. Here one finds friendship, forgiveness and the golden rule (Do onto others as you would want done to you.), reciprocity and the like.

The virtue of temperance concerns moderation in the pursuit of pleasures associated with food, alcohol and sex. Temperance or prudence involves the ability to monitor and control one's emotions and behavior in order to preserve one's health and maintain good relations with others. Without temperance one would not have the mental clarity to pursue wisdom or have the judgment for any of the virtues.

The virtue of transcendence concerns the belief in a larger purpose beyond self-interest. Transcendence involves an appreciation of beauty, gratitude, hope, a sense of humor and spirituality. It rejects cosmic nihilism, that life has no meaning, and affirms, whether in explicitly religious or nonreligious means, the value of human existence and the value of the community.

The virtue of wisdom is perhaps the most basic virtue. It is defined as having knowledge of the basic truths of life, especially self-knowledge, and the ethical application of this knowledge to real life situations. Wisdom means a rational open-mindedness, love of learning, and good judgment about the uncertainties of life. It has been defined as practical intelligence which maximizes one's own good and the good of others in a harmonious way. Wisdom incorporates the insight that knowledge, defined as justified true belief, is a kind of map of reality and as such is a necessary presupposition for the success of any human endeavor. Since wisdom presupposes truth and communication also presupposes it follows that without communication there is no social order. Without social order and trust a society cannot exist for long.

Moral norms and virtues are the solution to the problem of maintaining social order among members of a species who have social and anti-social tendencies. Moral virtues channel human impulses and actions into ordered relations with the actions of others. They constitute a structure of rules which define appropriate means for the achievement of ends with minimal conflict and inefficiency in meeting the needs of its members.

Anti-social activity is due to many factors. The scarcity of desired objects (food, wealth, status, etc.) differences in class, ideologies, moral and intellectual limitations, the dependency of persons and their vulnerability to attack by others may all play a role. Moral norms and their internalization as virtues are the solution to persons seeking the satisfaction of their needs in a social context without producing the Hobbesian state of war of all against all. Moral norms constitute the 'glue' that counteracts the centrifugal forces of unlimited and irrational self-interest. Moral norms limit the area of the unknown and unpredictable, reducing the frustration of expectations and minimizing conflict.

\section{SOCIAL Structure}

There are numerous kinds of societies in existence but no matter how diverse, some sociologists have plausibly argued that all societies must perform certain functions to continue in existence with minimal violence and disorder [12]. Specifically, Talcott Parsons has argued, in short, that society is a system of interrelated processes each which perform an essential function for the maintenance of the whole. According to Parsons, for a society to survive as a society it must successfully perform four necessary functions, adaptation, goal attainment, socialization or pattern maintenance and integration. Let us consider each in turn.

Just as individuals must adapt to survive so too a society to exist must adapt to its environment and solve problems. To adapt it must gain knowledge of its environment and make changes in the social system to enable the society to continue to survive and function in a rational manner. Adaptation and problem solving require knowledge and collective efforts require decision-making and cooperation to implement decisions. Cooperation requires communication which in turn requires a rule requiring truth-telling in at least most collective endeavors; random lying would eliminate trust and produce social chaos. Simply put, survival implies knowledge and cooperation, and knowledge implies adherence to truth and rejection of lying. Here the virtue of wisdom as a kind of knowledge is clearly operative. 
All stable and enduring social systems must provide for group survival. They strive to do this by successfully competing with hostile social groups and by extracting the necessities of life from the environment and producing the goods and services required. In addition to an efficient economy, for adaptation to be successful, the political structures must establish a monopoly of power and control a certain territory where the members of the community live to defend against enemies and control internal criminal elements. The virtue of wisdom is a necessity in the ability of a community to adapt which is enhanced by the expansion of knowledge and the development of new technology; these factors can all play a pivotal role in controlling the physical environment and extracting resources to provide for social needs. [13]

As already suggested, truth is a presupposition of knowledge which is itself a presupposition of the virtue of wisdom. However, the motivation to act in conformity to the norm preferring truth-telling does not arise by nature alone but must be a product of appropriate socialization. Human beings, because of their rationality and ability to organize and learn, are remarkably plastic and capable of adapting to a diverse range of environments. What adaptations and changes are made, their effectiveness and how they are implemented is in part determined by the nature and effectiveness of socialization, the complex psychological and social processes which transmit the cultural system form one generation to the next. The virtues of wisdom and humanity and transcendence are necessary for the process of socialization, the transference of knowledge to the new generation. Socialization presupposes an accurate representation of reality or knowledge, which is the basis of wisdom.

One purpose of socialization is the creation of sufficient motivation of the members to support and maintain the beliefs and values of the social system. This is primarily generated by the family and school system which will include the inculcation of moral values which deal with the proper relationship between members and the regulation of means to achieve goals. The internalization of ethical virtues and customs are central for legitimacy and social control where the majority of individuals accept the basic structure of the community, and work to support it against enemies internal and external to it. The socialization or internalization and institutionalization of these basic values and beliefs are the necessary conditions for social functioning. Proper socialization trains new members to conform to the norms of their community, contribute to its functioning and control potentially disruptive behavior.

For societies to continue to exist and for socialization to be successful, a society must produce, nurture and educate new members of that society. Sexual expression must be allowed but must conform to rational social norms to reduce conflict. The values implicit in this context are the encouragement of some form of family unit, the prohibition of the killing and violence against in-group members (except when socially sanctioned such as self-defense) and the production, nurture and socialization and training of infants. Without reproduction and nurture, societies would obviously cease to exist and without socialization into the cultural system would cease to function efficiently, be maladaptive and incapable of confronting hostile groups.

Adaptation and socialization are clearly necessary for societal order and survival. These functions necessitate the realization of certain goals if the existence of a society is to be more probable. These goals can be political, military, economic or social. Here all the key the virtues are relevant. First, wisdom requires that societal goals must be logically articulated, consistent, reasonable and rationally prioritized. Secondly, members of the given society must be sufficiently motivated to pursue collective goals such as the production of necessary goods and services and defense against enemies. Here the virtues of courage and justice are clearly relevant. A society without courageous individuals would not have a successful military and a society not perceived as just by its members would not motivate its members sufficiently to defend it against enemies.

To perform its necessary functions successfully, the political system must be perceived as legitimate. Legitimacy is the idea that the power wielded by the government is believed by the majority of the populace as morally and legally justified and applied for the common good. This is a key component of the virtue of justice and transcendence. Transcendence, the belief in the connection to a higher purpose, which could be humanity itself, contributes to the efficient actualization of social goals. The virtue of humanity or compassion contributes the social glue which reduces social conflict and tension. Clearly temperance, the control of natural appetite is also necessary to reduce conflict, and promote the health of members. And courage is essential for the successful completion of all challenging activities. To control fear and react rationally to difficult circumstances are essential for goal attainment.

Integration concerns the regulation and coordination of the main institutions of a rational society. Successful integration is necessary in order to minimize conflict, maximize efficiency and maintain sufficient unity to act as a group. This is achieved primarily by a common language, religion, family structures, customs and moral virtues. Societal integration implies all the virtues especially that of wisdom.

Wisdom is essential for knowledge and its proper application is essential to all social action. And wisdom shows that there are two mechanisms for integration, socialization and social control through promulgation of law and its enforcement. In socialization, the cultural patterns are internalized by individual members of society which, if successful, motivate members to generally conform to social norms and customs. Adequate socialization seeks to avoid cultural patterns which weaken the necessary degree of order by demanding too little of its members or by making impossible demands on society and thereby creating conflict.

The virtues of justice, temperance, humanity, courage and transcendence also contribute to social integration. Justice promotes the sense of legitimacy of the status quo, and temperance enhances human performance by maintaining health. Courage is essential in all endeavors to meet challenges and humanity unifies through compassionate action while transcendence adds added meaning, hence importance, to all human action. 


\section{CONCLUSION}

It is clear that the universality of some virtues is not a coincidence but a necessity. The requirements of social order, survival and individual flourishing presuppose the existence and implementation of central moral virtues found across all cultures. [14]

\section{REFERENCES}

[1] W. David, Moral Relativity, Berkeley, 1986, pp. 12-45.

[2] W. G., Folkways, Hacket, 1906, pp. 31-65;

[3] E. Westermarck, The Origin and Development of the Moral Ideas, Macmillan, 1906, pp. 5-11.

[4] J. P. Sartre, Existentialism is a Humanism, Hacket, pp. 12.
[5] M. Karl, Communist Manifesto, Hacket, pp. 25-9.

[6] C. Peterson and E. P. Martin, Seligman, Character Strengths and Virtues, Oxford, pp. 12-20.

[7] I. Kant, Foundations of the Metaphysics of Morals, Hacket, 1987, pp. 11-24.

[8] J. S. Mill, Utilitarianism, Hacket, 1967, pp.7-15.

[9] B. Ruth, Patterns of Culture, Oxford, 1934, pp. 23-26.

[10] C. Peterson, op., cit., pp. 23; Plato, Republic, Marx, op., cit., pp. 34

[11] Aristotle, Nicomachean Ethics, Cambridge, pp. 33-43.

[12] P. Talcott, The Social System, Harvard, pp. 154-65.

[13] P. Karl, The Open Society and It Enemies, Chicago, pp. 254-67.

[14] C. Roger and M. Slote, Virtue Ethics, Eds., Oxford, 1997.

Joseph Grcic is a professor of philosophy at Indiana State University. His latest published book is Free and Equal. 